\title{
Mysteries and Mysticism in the Arabian Desert
}

\author{
Majeed Khan \\ Saudi Commission for Tourism and Antiquities, Riyadh, Saudi Arabia
}

\begin{abstract}
Saudi Arabia is rich not only in its oil, but also in its cultural heritages. With 1,500 rock arts and 4,000 archaeological sites it is the fourth largest rock art region in the world. The entire Saudi Arabia has been comprehensively surveyed, investigated, and documented under the auspices of the Saudi Arabian Department of Antiquities (now Saudi Commission for Tourism and Antiquities). The archaeological and rock art investigations revealed tantalizing results providing the evidence of human presence in the Arabian Peninsula from the early Acheulean period until the present day. In addition to the ancient towns and cities like Madain Saleh (contemporary to Petra in Jordan), Tayma, Domat al-Jandal, Thaj, and al-Fao and Ukhdoud hundreds of strange, mysterious, and mystic structures and petrolyghs are located in the deserts of Arabia. A few of such sites are discussed in this paper, highlighting the strong but still unknown to the world the cultural heritage of Saudi Arabia.

Keywords: rock art of Saudi Arabia, mysterious and strange, stone structures, petrolygphs abstract, mythical and mystic images
\end{abstract}

\section{Introduction}

Saudi Arabia is usually considered as a sacred land of Muslims or the land of Arab Bedouins living in the desert far away from any civilization. With the name of Saudi Arabia, inflow in our eyes the scene of a barren wilderness, which since the dawn of history has even been at war with extremely hot, desert, and inhospitable environment. But, it is not so, the desert of Saudi Arabia contains hundreds of rock art sites and thousands of petroglyphs depicted on the rocks, hills, and mountains all over the country in addition to strange and mysterious stone structures and stone objects that are attributed to several millennia (see Figures 18 \& 25). With 4,000 archaeological and 1,500 rock art sites it stands among the fourth largest and richest rock art regions in the world (Bednarik \& Khan, 2002, 2005).

\section{Religious Icons}

Idols were worshipped in pre-Islamic Arabia. For the Bedouins (the desert nomads), it was not possible to build temples in the desert, which could be buried in the shifting sands (khan, 1990, 1991a, 1996). They however, created open air temples and depicted images of their deities and gods on rocks at higher places. Such open air worshipping sites could survive both the sand storms and shifting sand dunes. These are still preserved on several places in the deserts of Arabia.

In WadiDamm, northwest of Tabuk, northern Saudi Arabia, this composition of idol form (see Figure 3) and bull representations constitutes an open air temple. Bull was a sacred animal both in prehistoric Arabia and in Egypt. The panel is located at about five meters high on the smooth sand stone hill surface. High skilled

Majeed Khan, Ph.D., consultant, Saudi Commission for Tourism and Antiquities. 
efforts were used in creating this splendid and amazing work of art that still survived after several centuries of its creation. Perhaps offerings were placed in the crevasses under the rock art panel and the priest might be sitting in a small rock shelter (extreme left). Date unknown.

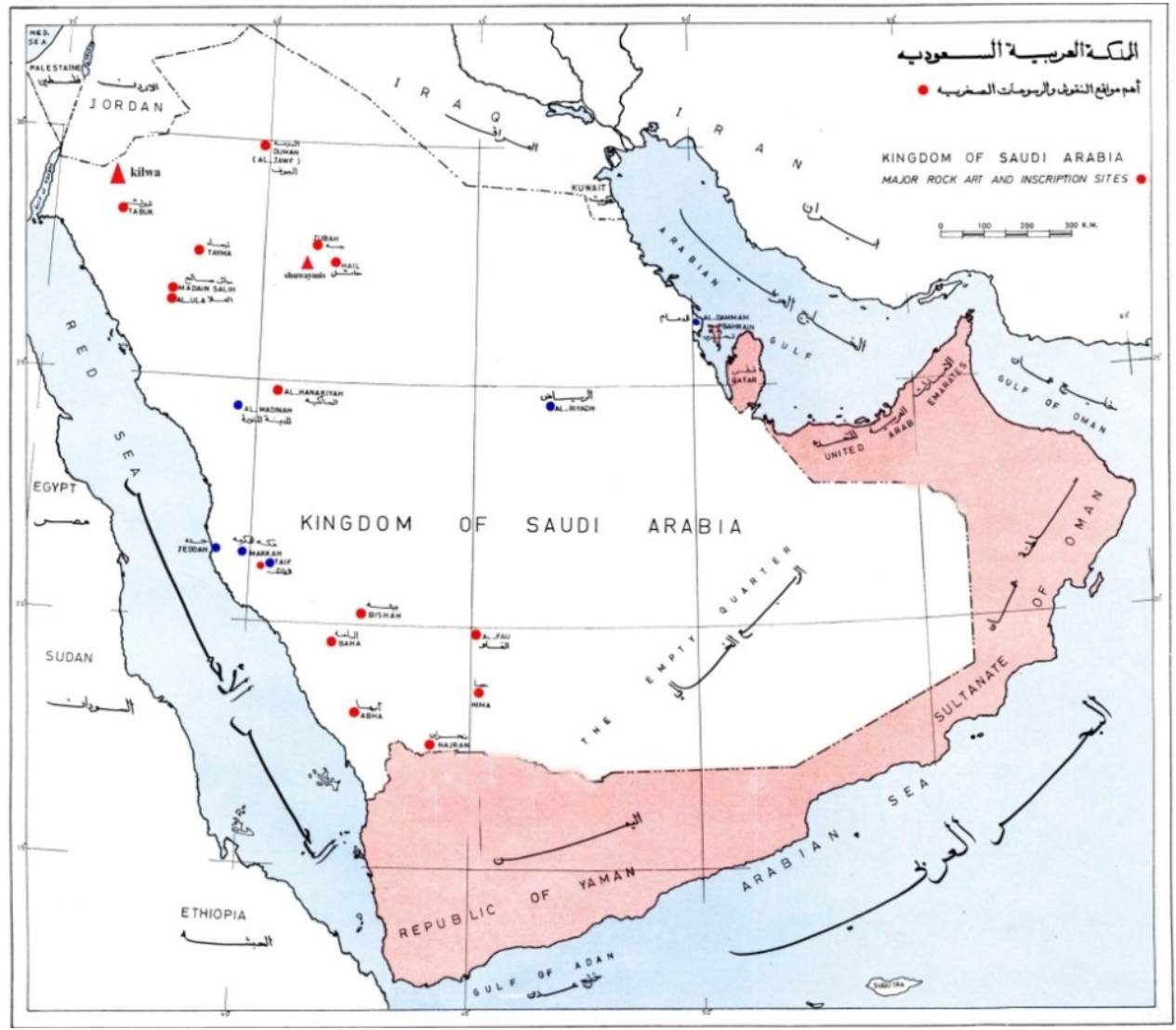

Figure 1. Map showing major rock art sites in Saudi Arabia.

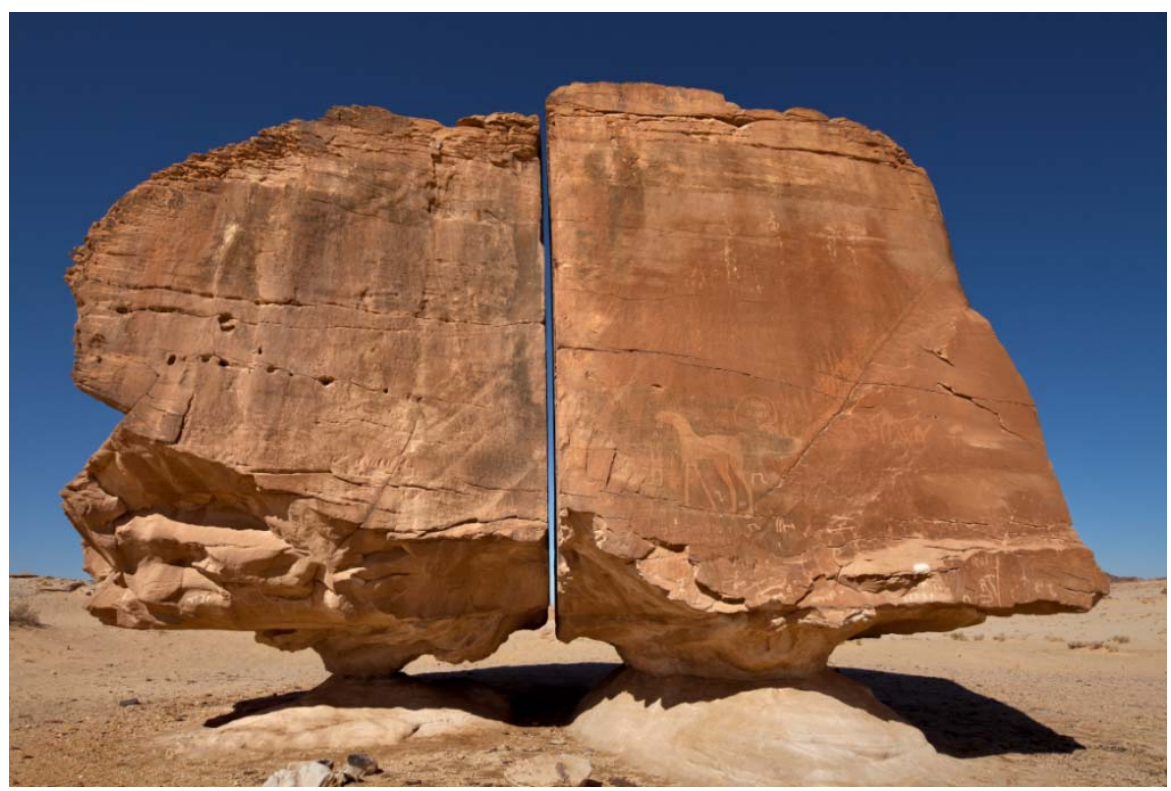

Figure 2. Split rock as if cut by a razor, Tayma, NW Region. 


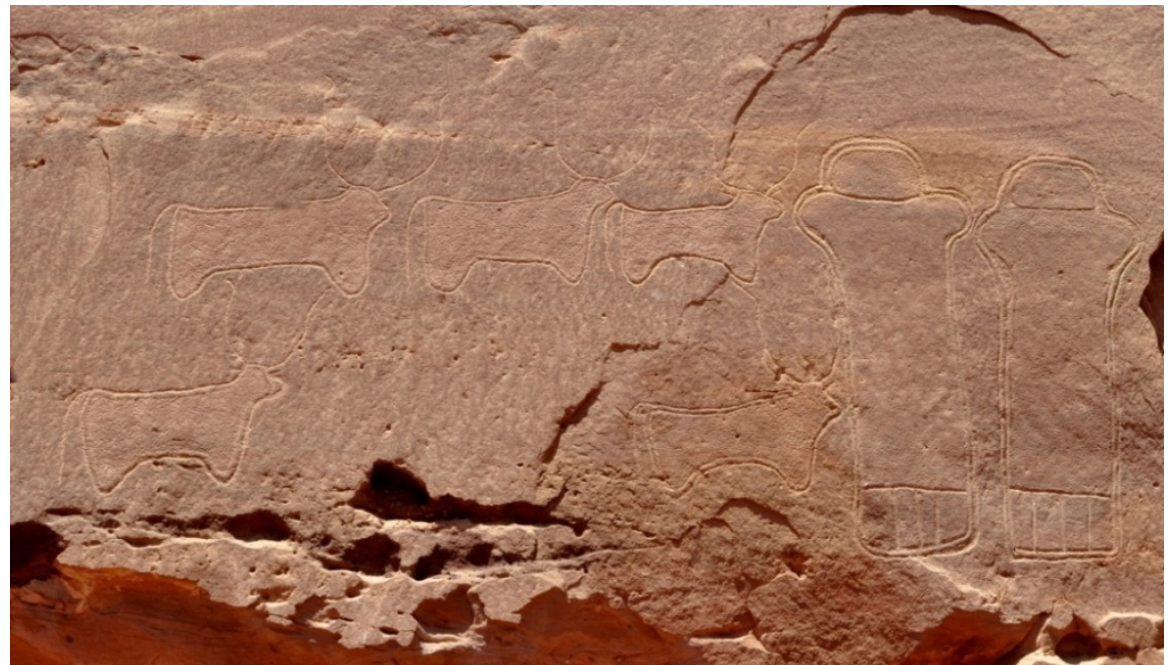

Figure 3. An open air temple, images of idols and sacred bulls were carved on the vertical surface of a hill and worshipped.

Several figures of "Alia” (known among the local Bedouins) the Pre-Islamic goddesses are located on a prominent higher and vertical surface of a hill (see Figure 4). The site is situated near a water body, now dry, but was possibly a spring or rain water reservoir in the past. Rock shelters, availability of water and some plants in the area made it a perfect site for social and religious gatherings. Rituals might have been performed and on each occasion, yearly or whatever it was, the icon of the goddess was created on the same site (Khan, 1990, 2000b). The site continued to be a gathering place for long as there are hundreds of ancient Arabian inscriptions engraved all around the water reservoir on the hill surface. Dated c. 1500-1000 B.C..

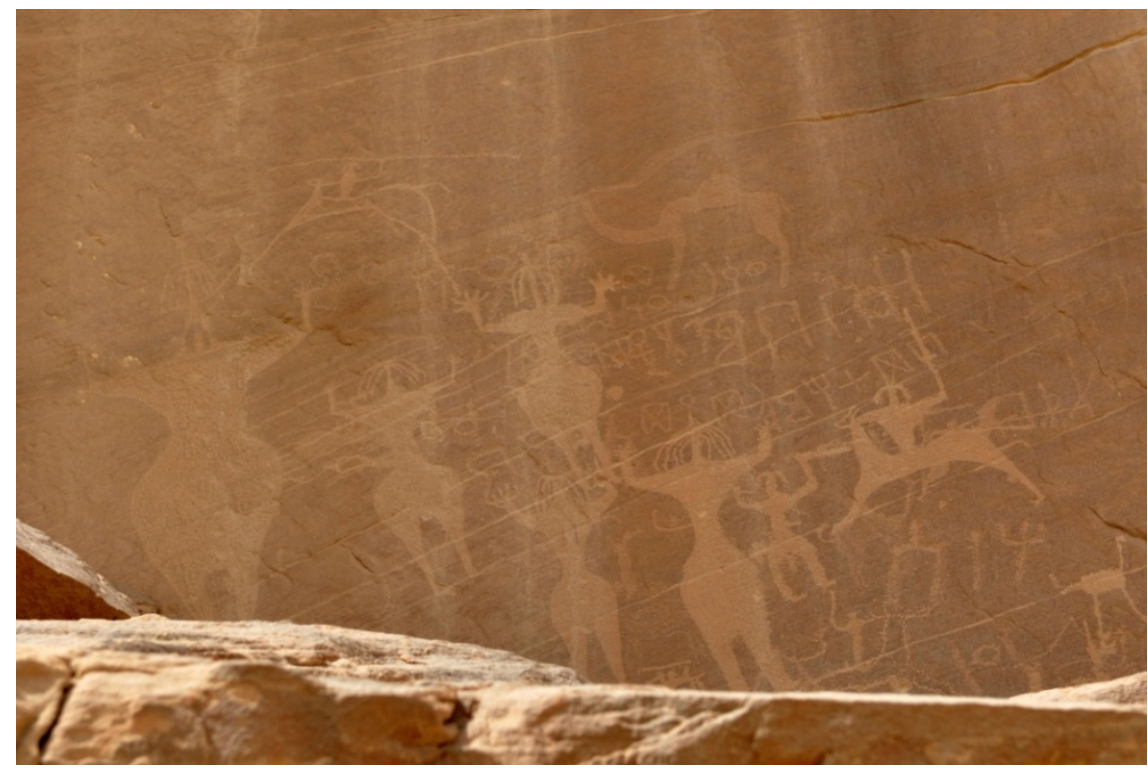

Figure 4. The images of Alia are found in large number in southern Arabia and northern Yemen. ${ }^{2}$

\footnotetext{
${ }^{1}$ Located in Tabuk area, northwest of Saudi Arabia. Date unknown, but could be tentatively attributed to 3rd millennium B.C..

2 These are roughly spread in a triangular area from Yemen to southern Arabia representing a homogeneity in culture, religion, and cosmology in a wide area. Here on this particular rock and place different people approached at different times but in the same cultural period to create images of their goddess and making it as an open air temple in the desert of southern Arabia, Najran.
} 
The icons of goddess Alia commonly found in the rock art of southern Arabia refer to some abstract qualities embodied in them (see Figure 5). It may be the goddess of love and fertility as sexual traits are more prominently depicted on them. The images are apparently impressive and expressive in their appearance. Obviously, these figures meant to articulate cognitive contents to be selectively communicated across time from generation to generation or across space. If one considers that for nomads the most efficient way to create places of worship is to use the rocks as their medium, otherwise permanent built temples could be wiped away by strong wind and sandstorm and buried under the moving sand dunes. Thus, religious icons fulfill symbolic function and are combined with some sort of syntax related to beliefs and religious ideologies. The rock and the hills, where prehistoric people depicted images of their gods and goddesses, should have been sacred places for worshipping and religious rites.

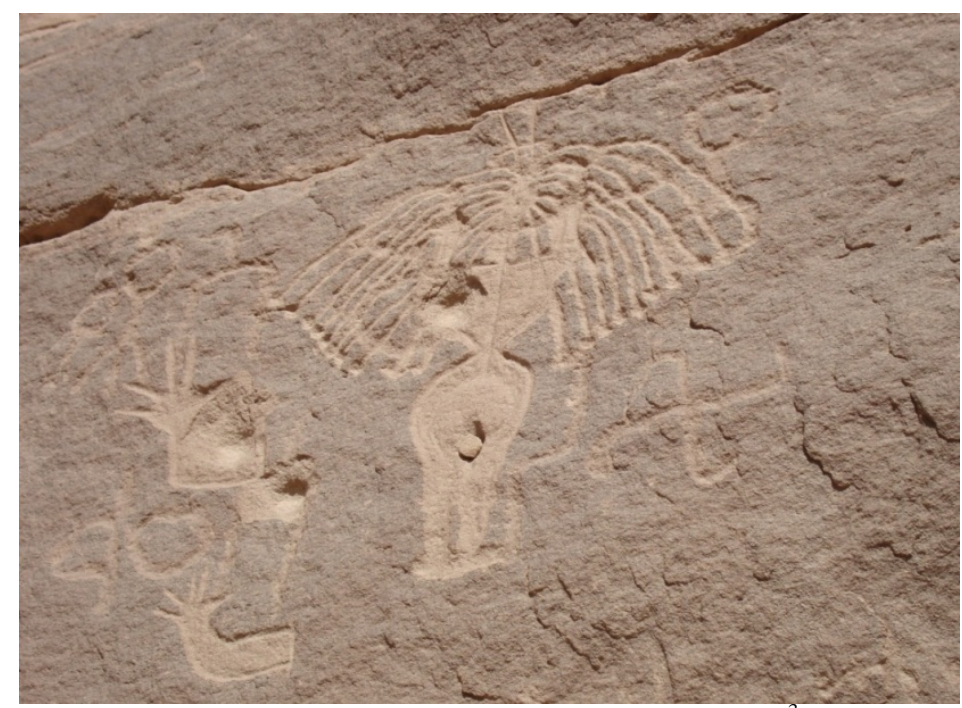

Figure 5. Possibly the image of the goddess Alia. ${ }^{3}$

It appears from these pictures of the goddesses that the artist/artists were working within certain limitations and they adopted the same pattern, style, and subject without freedom of choice (Khan, 1990, 1993c, 2007). There were probably artists of religion who imitate the images of their deities and do not bring any change either in style, form, shape, or subject matter. It is why on almost all the sites we found identical images of the so called goddess "Alia". There should have been some professional artists who worked within certain cultural and religious boundaries making only those figures which were allowed by the society and strictly following the regulations. Therefore, we do not find variety of artistic activities and any colorful aesthetic creations.

\section{The Oldest Rock Art in Arabia}

In figures $6 a$ and $6 b^{4}$, the striking image is that of a throwing stick (indicated by black arrows) which looks like the boomeragne usually assoicated with the Australian aborgines and does not found any where else. If this is a neolithic representation, then boomerage was first originited in Arabia and not in Australia or Africa. An

\footnotetext{
3 The arms are shown as if in supplication to the goddess asking her favor and blessings. The figures are damaged by shooting as the Bedouins often used them as a target for shooting.

${ }^{4}$ They are attributed to the Neolithic period c. 9500-9000 years before present.
} 
animal, probably a bovid is associated with the anthropomorphic representation holding throwing stick or boomernage while in the other figure people are carrying a hunted animal. In each case the face is ambiguous, body long and slender, and legs slighlty bent. It is difficult to recognize them as full human figures that could possibly be the images of deities or creatures of metaphysical world. Such human forms are depicted on several sites at Jubbah and Shuwaymis north of the country.

The Arab nomads, locally called as "Bedouins", do represent a culture the roots of which could be traced far back in prehistory, but it must be clear that they had or have nothing that may support the western notion of a tribe as a vestige of savagery and barbarism. Yet, tribal system still exists in Arabia that maintains strong social and cultural traditions since antiquity.

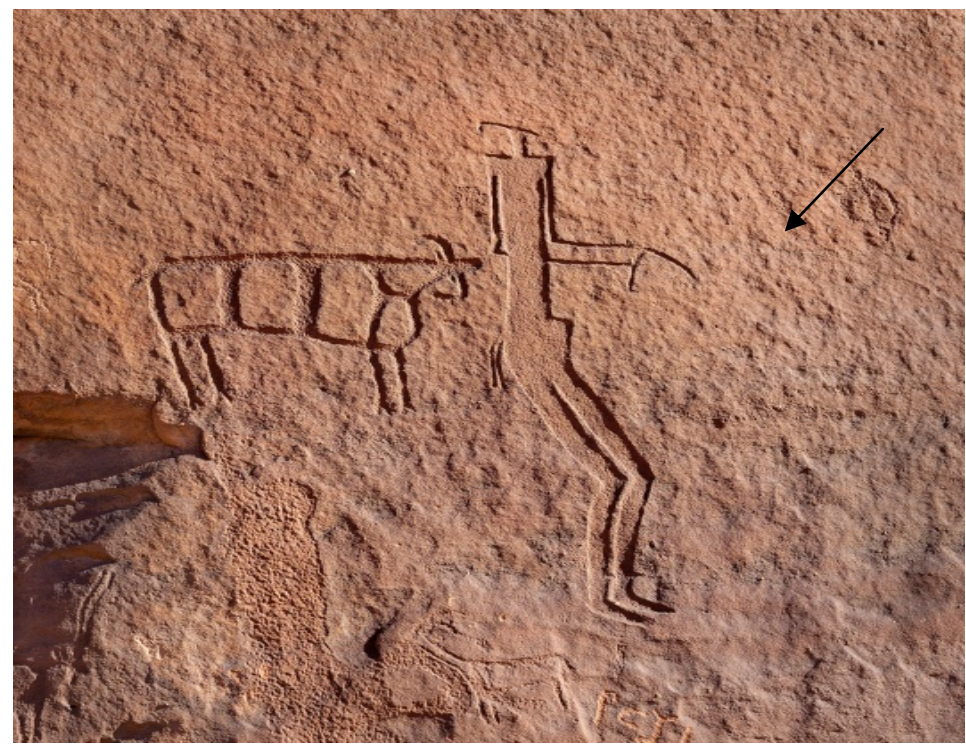

Figure 6a. Strange and mysterious human forms depicted on the vertical surface of a hill at Jubbah north of the country.

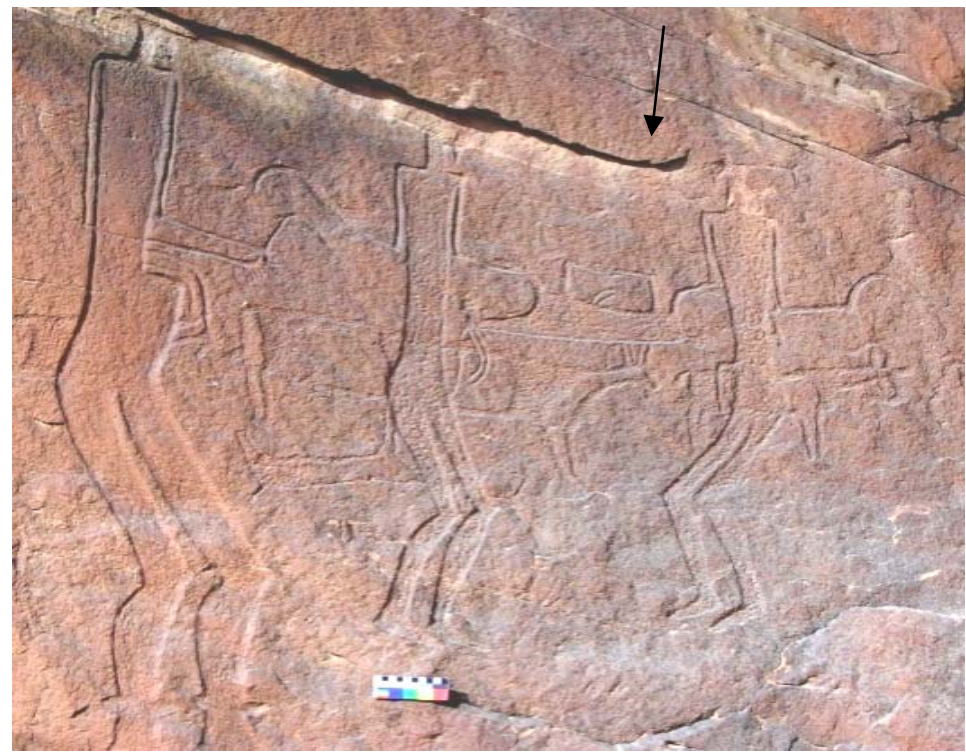

Figure $6 b$. Strange and mysterious human forms depicted on the vertical surface of a hill at Jubbah north of the country. 


\section{Centuries Old Bedouin Traditions}

The nomads or the Bedouins are the essential part of the Arabian Desert which is their motherland; in fact, they are the true perseverance of original Arab races, traditions, social, and cultural values. In spite of all modern developments which entered the Arabian Peninsula during the last decades, the tribal system of life could not be affected and the Bedouins, who have now adapted to the modern life style surprisingly, still maintain their original social and cultural values. They are proud of their traditions, love their land, and still spent their vacations camping in the desert in the same traditional style that they have preserved for thousands of years.

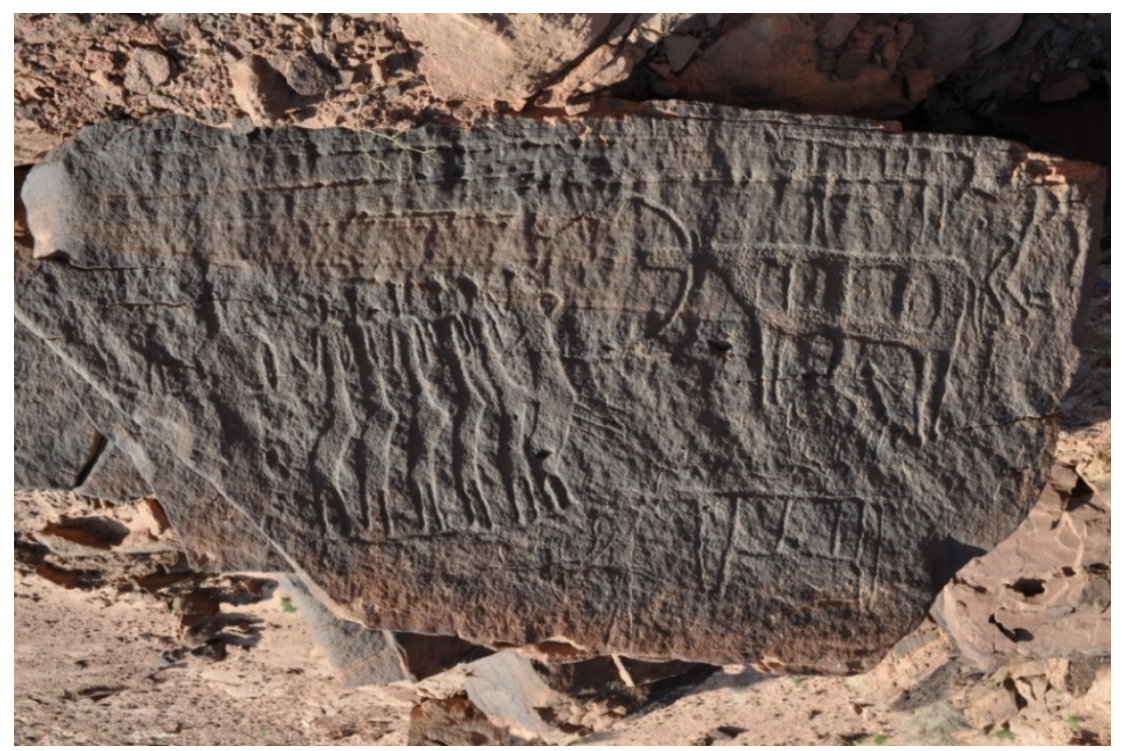

Figure 7. Dance in the desert similar to somewhat Bedouin dances that are still danced in social activities.

Hundreds and thousands of rock art sites are located all over the country. The art could be attributed to the prehistoric and tribal periods such as hunting camel (see Figure 17). Some of the Arabian dances (see Figure 7) and art contents show a continuity of tribal art from times unknown (Khan, Kabawi, Al-Zhrani, 1986). Consequently, it is tempting to see modern Bedouin or tribal attitudes to tribal affinity, cultural and social values and their dances as survival of cultural tradition that can be traced far back into prehistory (Khan, 1993c, 2005).

\section{Foot and Hand Prints}

Earliest evidence of human presence in Arabia shows the foot prints deeply pecked on the horizontal surface of a hard sandstone rock at Shuwaymis, northern Saudi Arabia (see Figure 8). The almost natural size foot prints hoof and cup marks are pecked deeply in the rock. The fingers, the toe and overall shape of the feet suggest that these are the foot prints of the people who depicted it as memorial signs or for some other reason, are very well preserved for thousands of years. This is the oldest foot print in the Arabian Peninsula that could be attributed to c. 12,000-10,000 years B.P. (Bednarik \& Khan, 2005).

The gradual change in style, contents, context, and conceptuality from prehistoric to Bedouin or tribal art could be clearly defined on the basis of animal representations, tribal symbols, and Bedouin writing that developed later in the early Iron Age (Khan, 1993b, 2000a). Bedouin folk dances, branded camel figures and the names of tribes and persons engraved besides rock art compositions testify to the fact that rock art played an 
important role in describing the social, cultural, and religious entities of Arabia from prehistoric to the early Islamic period (see Figure 9).

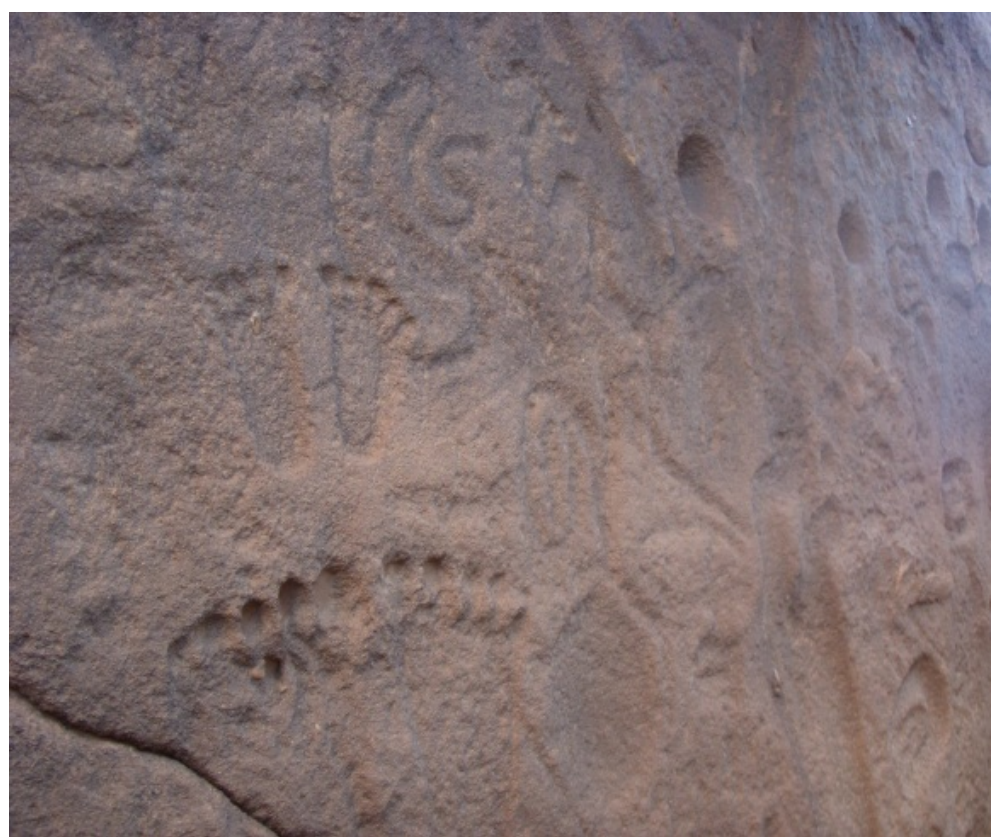

Figure 8. Footprints, cup, and hoof marks are deeply pecked on the horizontal surface at Shuwaymis dated 12,000 years before represent, the earliest evidence of human presence in Arabia.

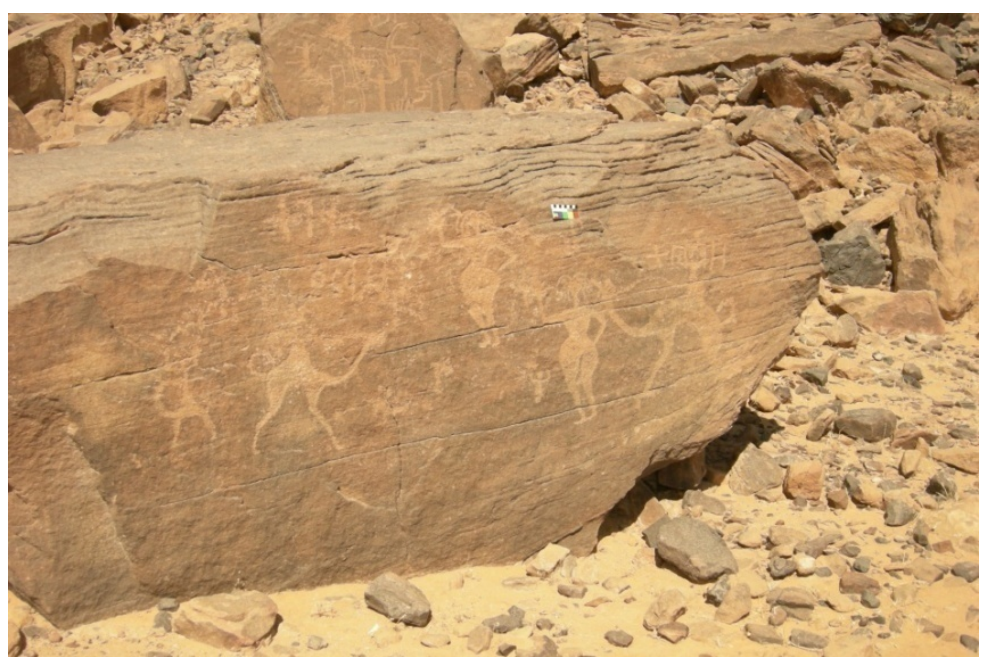

Figure 9. Dancing in the desert, camel being involved in the ritual or the ceremonial dance. ${ }^{5}$

With the establishment of large scale communities, developments of tribes and clans, and beginning of large scale domestication of camels appeared the use of animal brands or locally called as Wusum. In Arabia Wusum or animal brands were used for several purposes and were multifunctional such as marking territorial boundaries of tribes, as symbol of tribes, signature on documents, grave marks and as property brands depicted on tents and camping sites (Field, 1952; Khan, 1993b, 2000a).

Although branding animals is a worldwide phenomenon and is still practiced and depicted on horses and

\footnotetext{
${ }^{5}$ The artist has created a beautiful dancing scene in association with camels which was and still is the most loving and most valuable animal for the Bedouins.
} 
cattle etc.; in Arabia, it is a deeply rooted ancient tradition. The pristine Arab tribes, still living in the desert called "Bedouins", use certain geometric and non-representational motifs as "Tribal Symbols". These Arab tribes being confined to their territories since antiquity are still holding intact their social and cultural value.

The principal on which the system of Wusum operates consists of a complex combination of non-phonetic characters. It constitutes a coded system used only for a limited purpose. The Wusum therefore, consists of symbols that have connection with the language or writing and that expresses meaning directly. The signs are epistemic or semantic unrelated to utterances, just like international traffic signs that have no relationship with any language but are understood by all (see Figure 10).

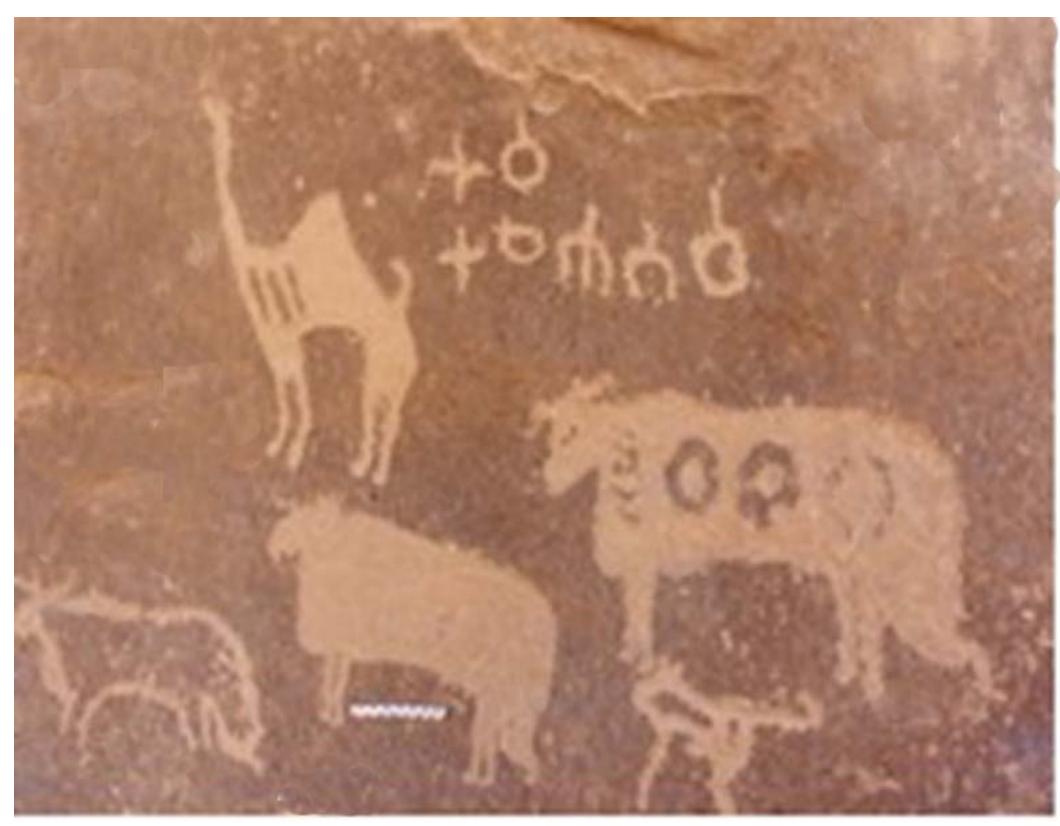

Figure 10. Wasum or camel brands/tribal symbols still used by the Arab Bedouins.

For a long time, archaeologists had the idea that pastoralists and nomadic Bedouins living in harsh and desert environment would leave little or no records of their presence. But, recent archaeological, rock art surveys, and investigations have not only dismissed all previous assumptions, on the contrary revealed a tremendous amount of cultural material in the deserts of Saudi Arabia.

It is very interesting that the rock art of Saudi Arabia represents the same animals with which the local population was aware and which were found in this part of the world such as cattle, camel, deer, gazelles, dogs, snakes, lizards, and goats etc.. Surprisingly no flora (with the exception of a couple of sites with date trees) and no birds except ostriches were depicted. Thus, the artists chose some animals from their environment and depicted them on the rocks and overlooked other animals which were as good for them and were part of their ecology and environment (see Figures 11, 12, \& 13). It is thus, a universal phenomenon and everywhere in Europe, Africa, Australia, or Asia the same tendency has been observed. It means that artists in various parts of the world had the same intellectual, ideological, and mental approach (Khan, 1993c).

The chronology of rock art from Neolithic (12,000 Years before present) until the early Islamic period is the proof that the aesthetic urge and the intention to preserve cultural heritage are not recent refinement of human civilization but part of ancient deeply rooted activity of our ancestors. 


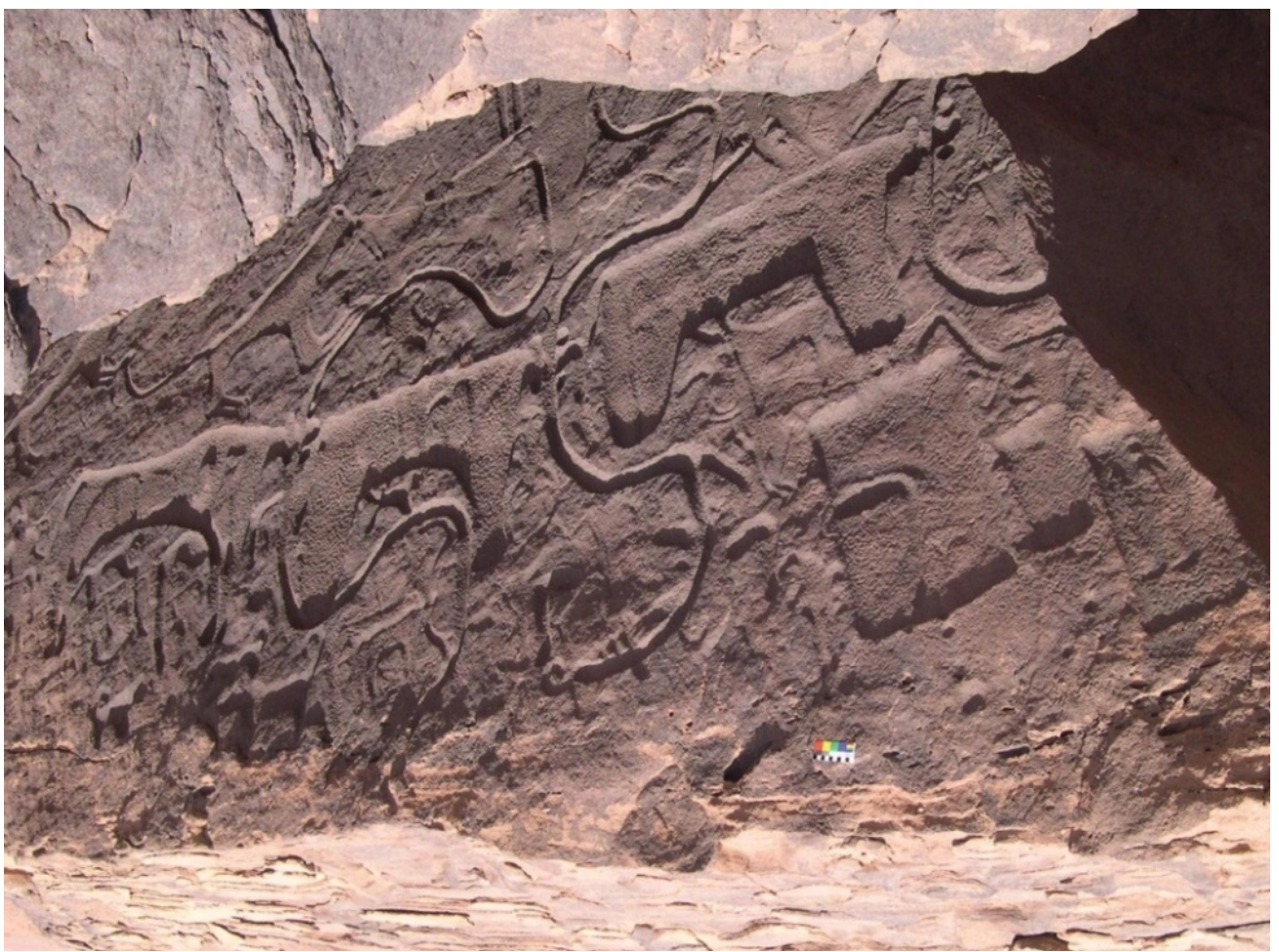

Figure 11. Bovid with extraordinary large curved horns and cheetahs carved in bas-relief on a large rock boulder at Shuwaymis, northern region. ${ }^{6}$

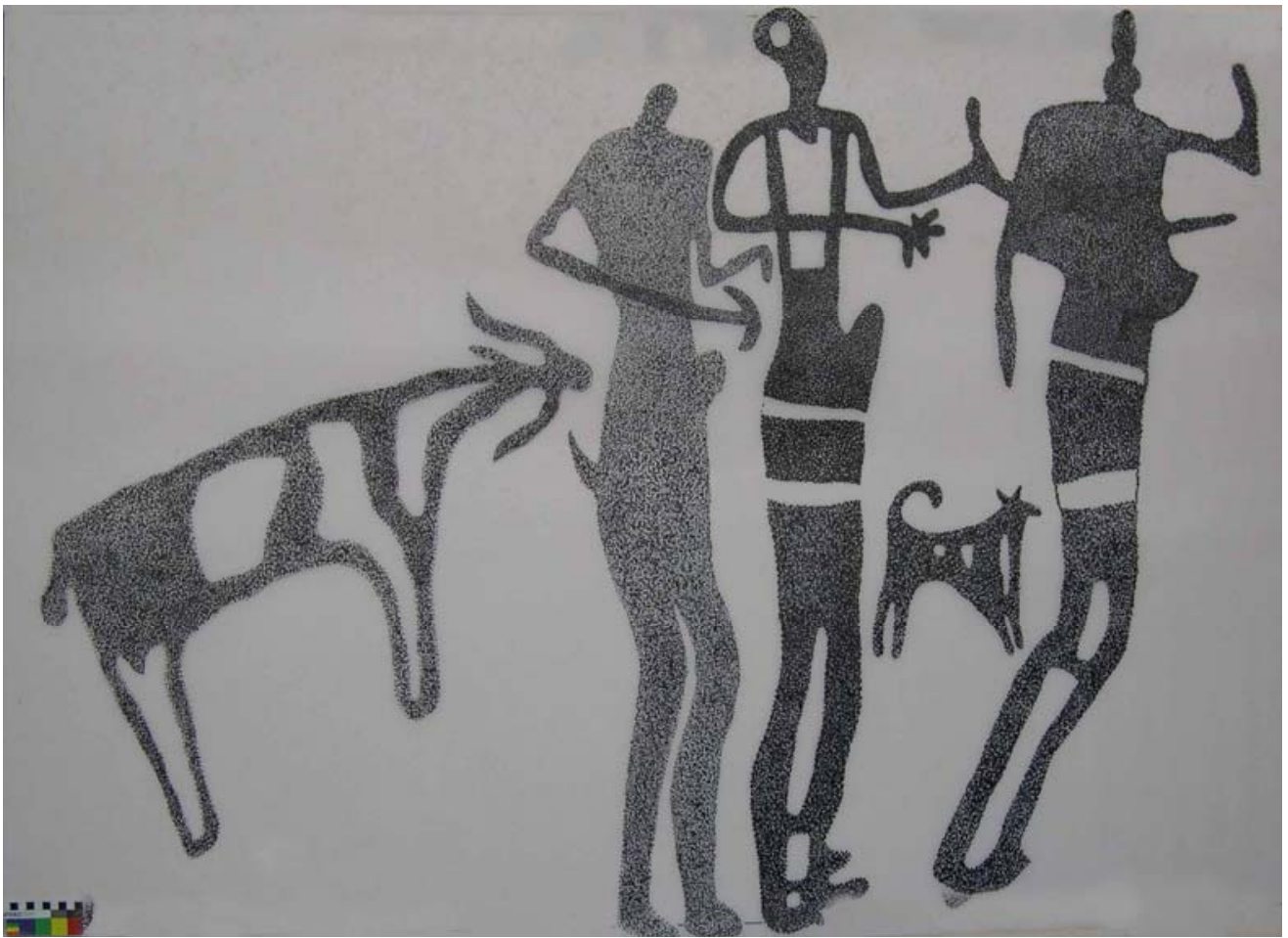

Figure 12. Abstract human forms, perhaps images of metaphysical world,

${ }^{6}$ The horns are even bigger than the body of the animal showing perhaps abstract, mysterious mystic ideology associated with the bovid or over all composition. 
Located at the Neolithic site of Jubbah, Northern region.

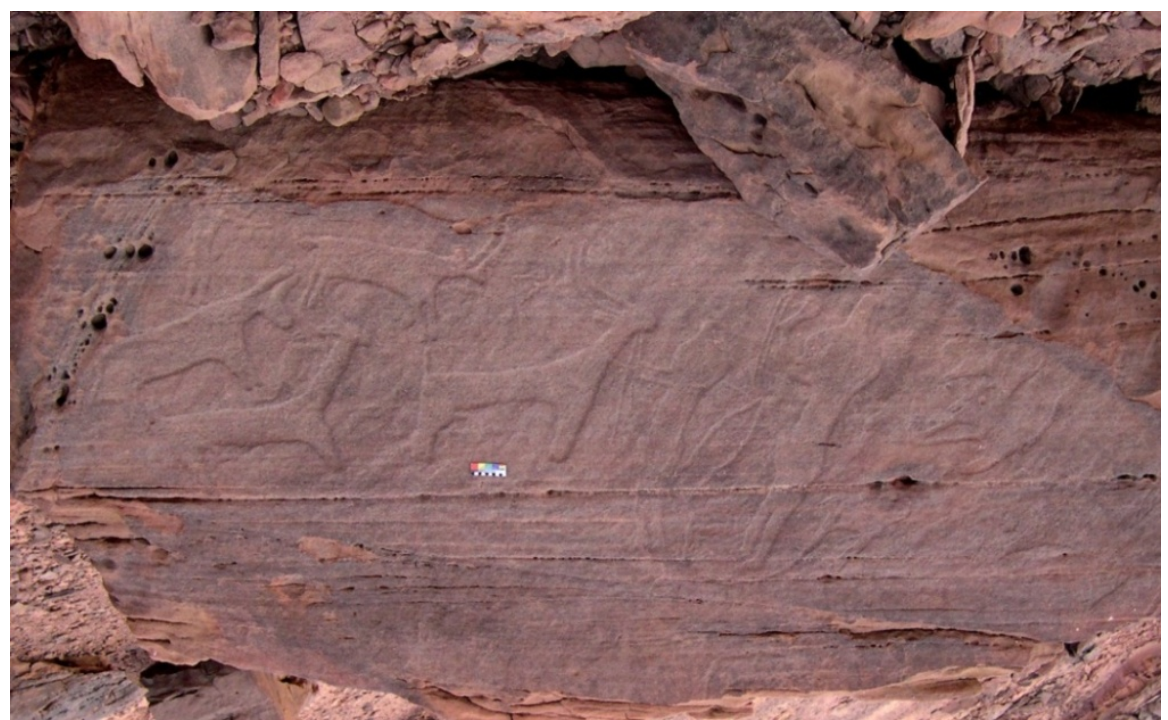

Figure 13. Human from holding simple bow and arrows pointing towards some animals apparently seems to be a symbolic scene representing animals of that time such as goats and equine etc.. Located at Shuwaymis, northern region.

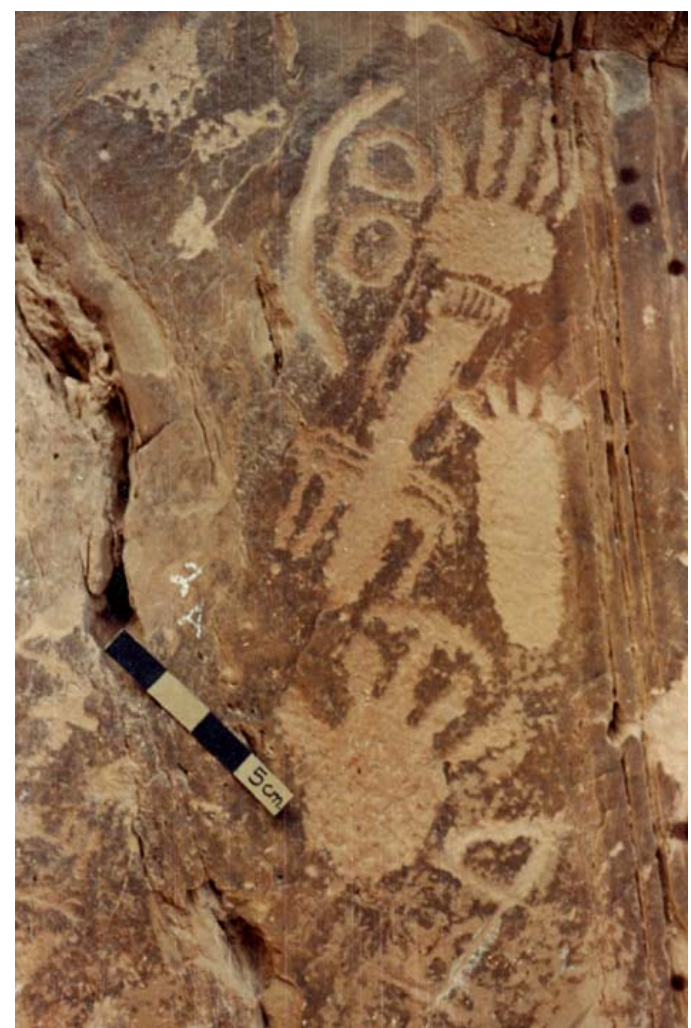

Figure 14. A composition of various motifs perhaps magical signs Carved by a Shaman.

\footnotetext{
${ }^{7}$ Perhaps symbolism, abstraction, Shamanic, or mysticism representation of certain motifs making a strange and mysterious composition located on the horizontal surface of a rock in northern Saudi Arabia. The arrangement of hand and foot prints in association with crescent shaped figure and a torch under the palm are together give the sense of a magical, mystical, and
} 


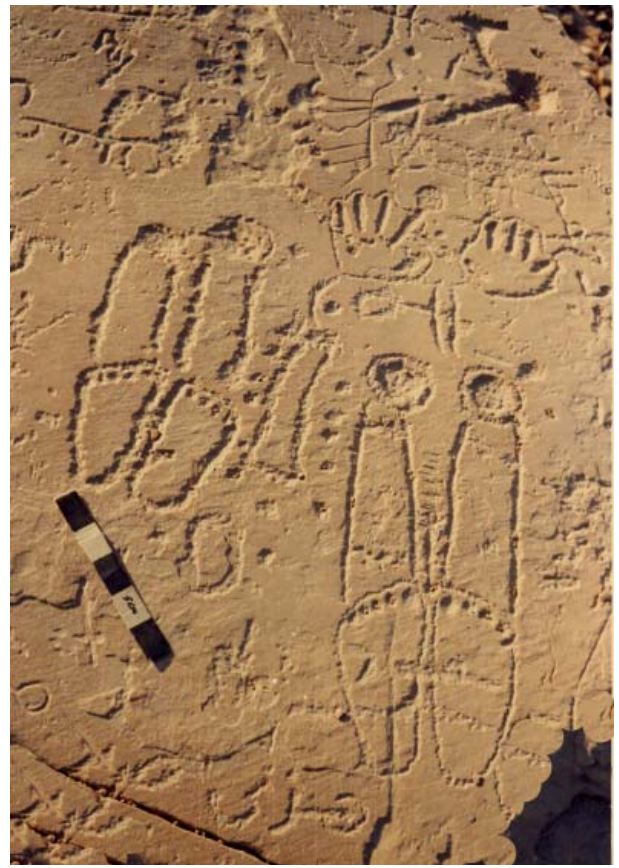

Figure 15. Foot and hand prints with Capoules. Feet like that of Buddha.

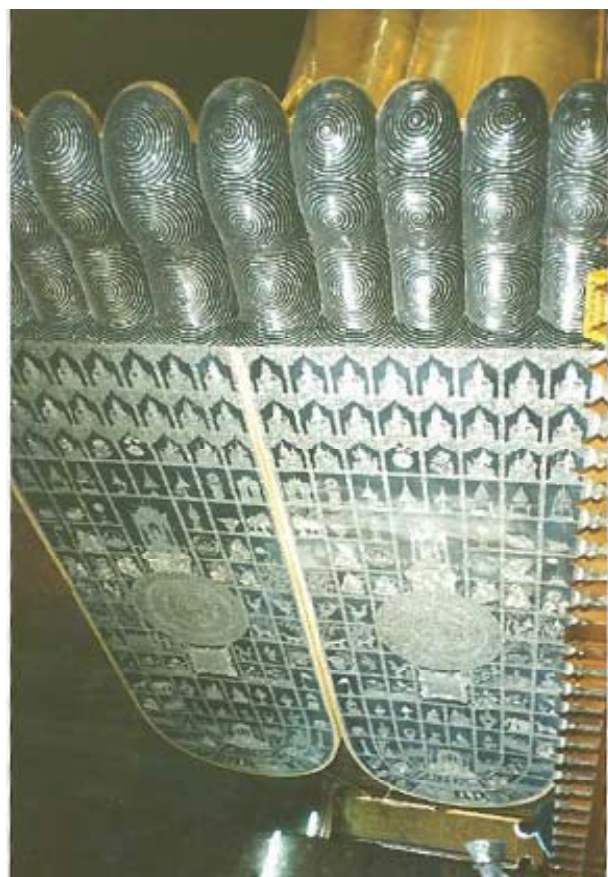

Figure 16. Foot prints of Buddha in a temple, Thailand.

Hand and foot prints are a common element found in almost all rock art regions of the word (see Figures $14,15, \& 16)$. These vary in contents and context but contain symbolic meanings in different cultures. Here at

Shamanic message. Although with our modern thoughts and ideas we cannot understand or interpret the real meaning of the panel but we can only guess according to what we see and we think about it. 
Sakkaka the cup marks are shown as head and on long rectangular body very large foot is shown just like we see on a Budha body in one of the temples in Bankok, Thailand (see Figure 16). There apparently seems to be the similar religious mysticism prevailed in the two different religions at far of distance and in different times.

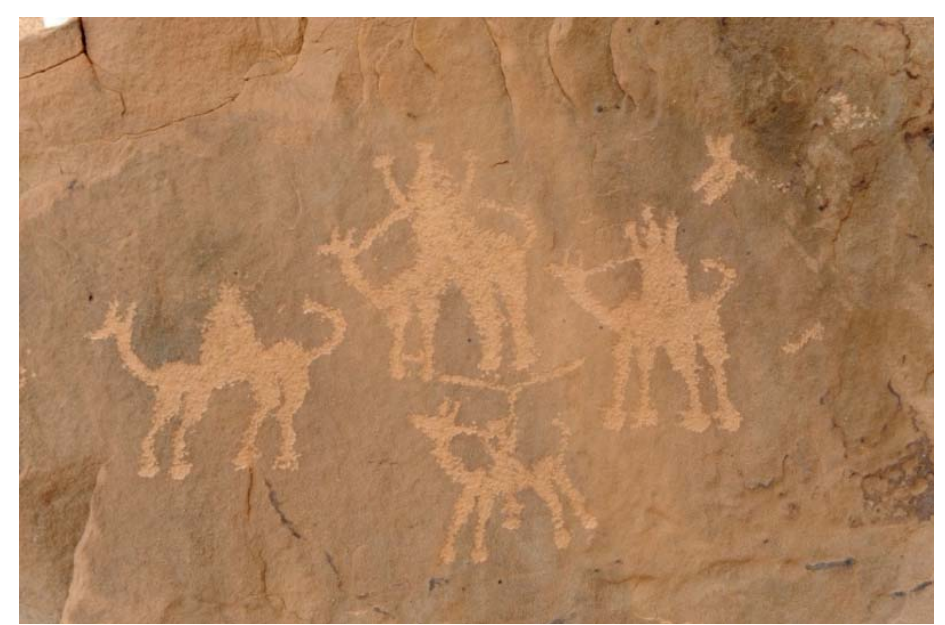

Figure 17. Camel riders following a camel, perhaps catching or hunting it. Jabal al Kaukab, Najran. ${ }^{8}$

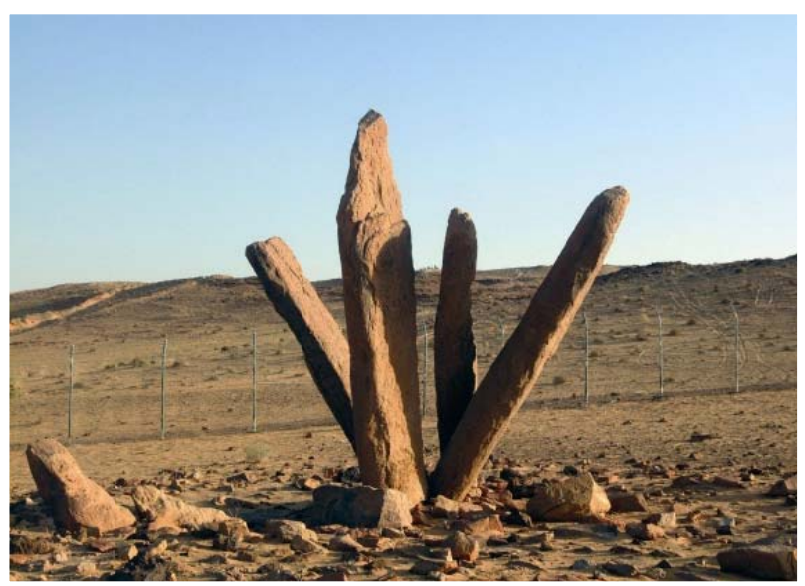

Figure 18. Standing stones at Sakkaka.

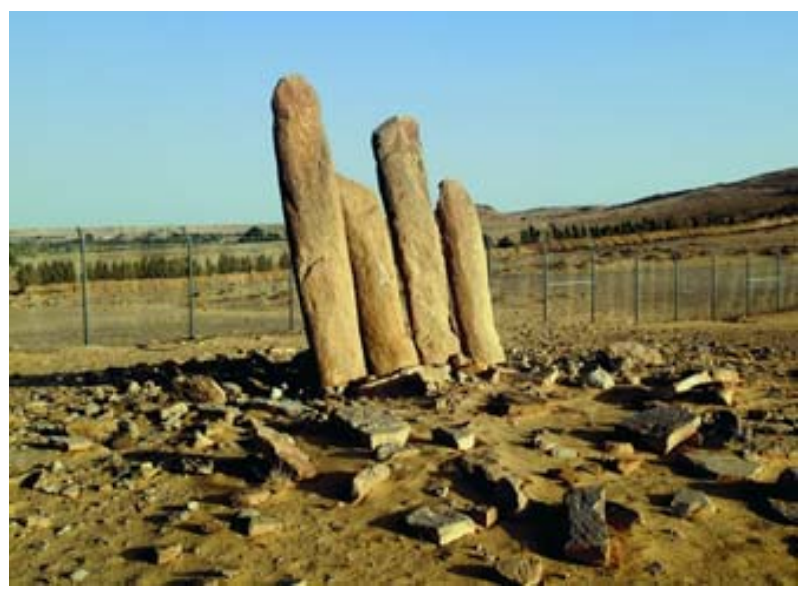

Figure 19. Orignal form of standing stones at Sakkaka.

\footnotetext{
${ }^{8}$ Does it mean the wild camel was existed in Arabia side by side the domesticated on.
} 


\section{Mysterious Stone Structures}

Standing stones in mid desert at Sakkaka, northern region of the country pose a problem of understanding their purpose, function, and reason (see Figures 18 \& 19). The stones are large over 3.50 meter long and approximately $75 \mathrm{~cm}$ wide. Originally these were standing close to each other in a straight line axis in a true north-south alignment. Thus the pillars faced east or general direction of the rising sun. However, these are inclined outwardly due to the effect of wind in thousands of years (see Figure 18). A group of over a dozen such stone pillars units are found standing in an area of about 500 meters. It is yet not clear from where these stones were brought and how they were cut and shaped in rectangular form at a time when there were no metal in use. These are attributed to fourth or third millennium B.C. (Zarins, 1979). No such site, similar to Rajajl, has been located in the entire country. Perhaps these structures served some religious or cultic function. In excavations around and near the rock no cultural material is found to support the reason or interpretation of these standing rocks. Although some figures and inscriptions are engraved on these pillars but these are later additions and it is evident from other standing pillars that there was nothing inscribed on these rock when these were originally erected. One of the pillar site was excavated in 1979 but no cultural material was found, thus making the site mysterious and un-understandable. However, in excavations of nearby area flint objects were found, which provided strongest evidence for dating the pillar site. Zarins (1979) claims that we can argue that our cultural material belongs to the general Chalcolithic tradition of the Near East to the fourth millennium B.C..

The standing stones were brought from somewhere else as there is no location near the site from where the rocks might have been bought, cut, shaped, and place on the site. The mystery remained unsolved as there is no residential site or remains of any structures that could be attributed to the site.

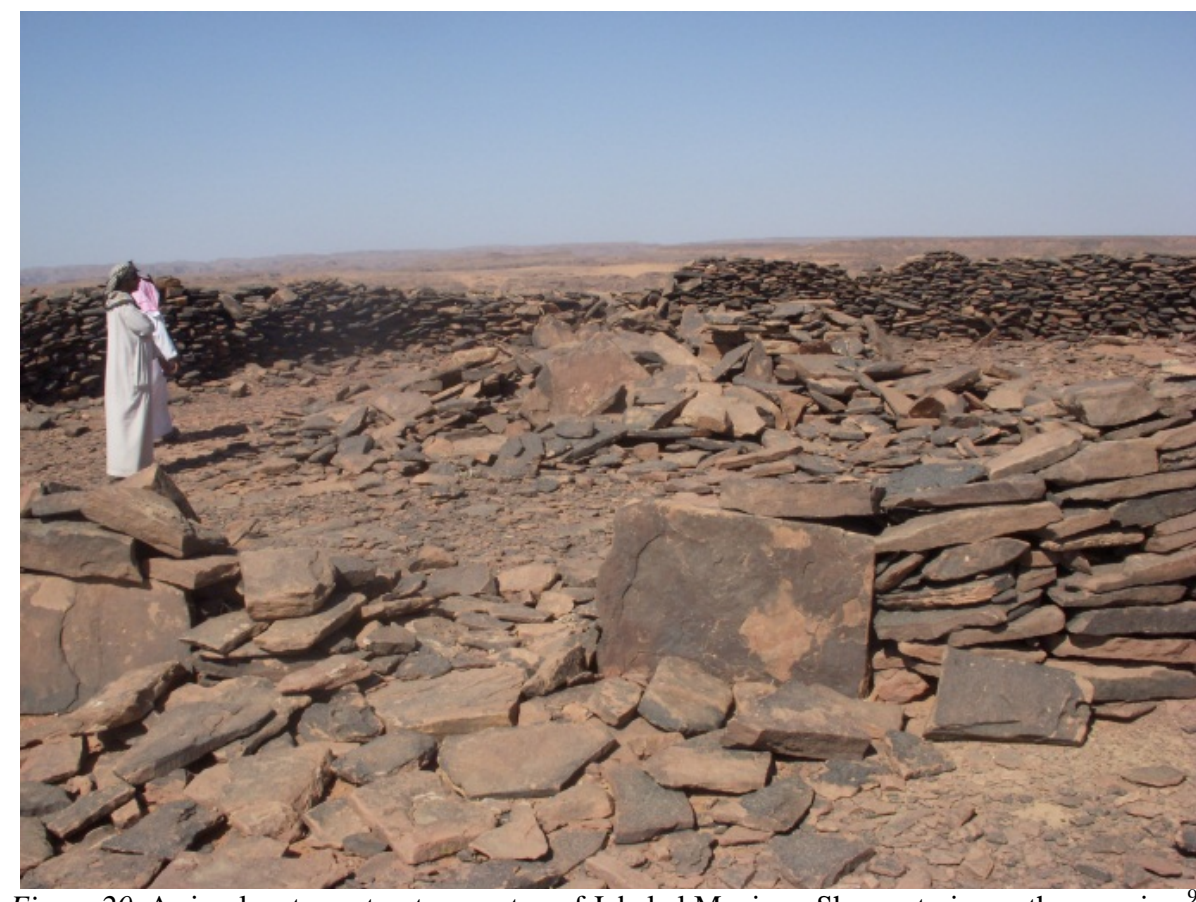

Figure 20. A circular stone structure on top of Jabal al Manjour, Shuwaytmis, northern region.

\footnotetext{
${ }^{9}$ In the middle of large circular structure there is a small pile of stones probably was a platform.
} 


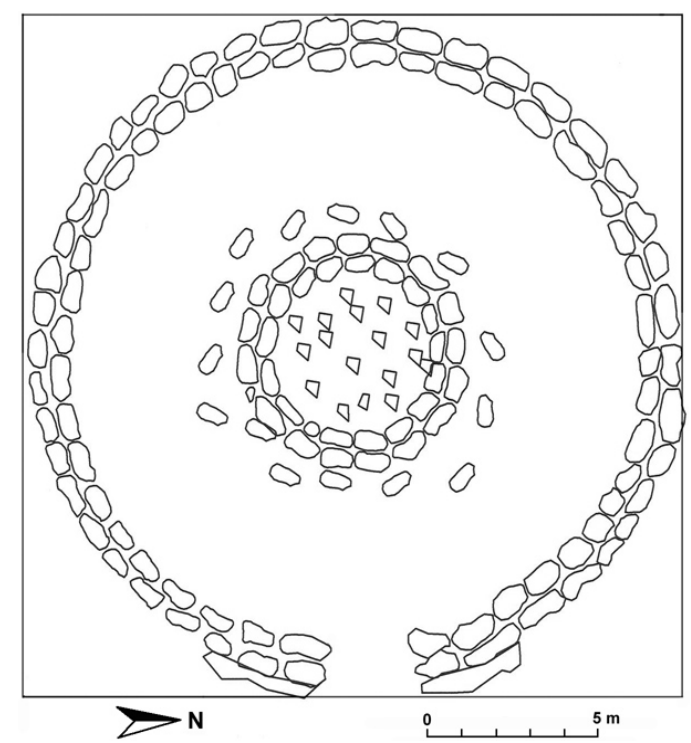

Figure 21. Plan view of the stone structure.

At Shuwaymis, some stone structures are located on the elevated areas besides the wadi at Jabal al-Manjor (see Figures $20 \& 21$ ). These are circular or roughly square-shaped structures. Although it is as yet not possible to positively link them with any of the Shuwaymis rock art the alignment of several extensive stone structures along the margin of the plateau overlooking the dense concentration of petroglyph clusters at Jabal al-Manjor is suggestive of a connection between these structures and one of the rock art phases evident on the cliffs below them. Most particularly, the large central ruin, above petroglyph cluster, does not appear to be a burial monument, but has the appearance of a ritual centre of some kind. It is based on a square stone platform erected hard against the edge of the plateau. On this base a circular wall with a diameter of about $25 \mathrm{~m}$ surrounds a paved courtyard that has an opening facing away from the escarpment's edge. In its centre appears to have been a small structure and there are further stone features that seem indicative of specific purposes (see Figure 21, 22, $23 \& 24)$.

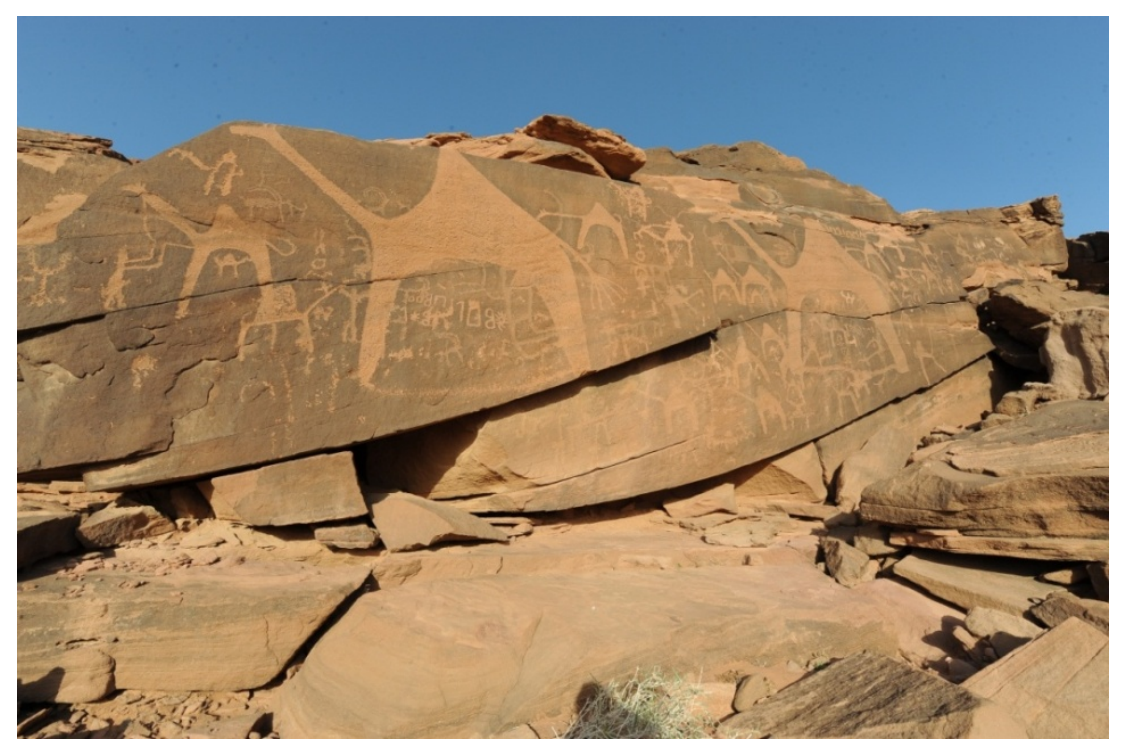


Figure 22. Camel figures on the facade of Jabel alManjour over which stone structures are built.

The structure's minimum age is indicated by the presence of one elongate stone slab outside the circular wall, which seems to have fallen from the structure and on whose upper side are the petroglyphs of "camels" of limited patination. Safely attributable to the last two millennia, this suggests a greater age of the structure, but as these stone structures are not known from the Neolithic, these are perhaps most likely of the Bronze Age. Although this is speculation, it is confirmed by the observation of numerous relatively late petroglyphs at other stone structures at Wadi al-Mukhayet and nearby sites of Jabal al-Manjour.

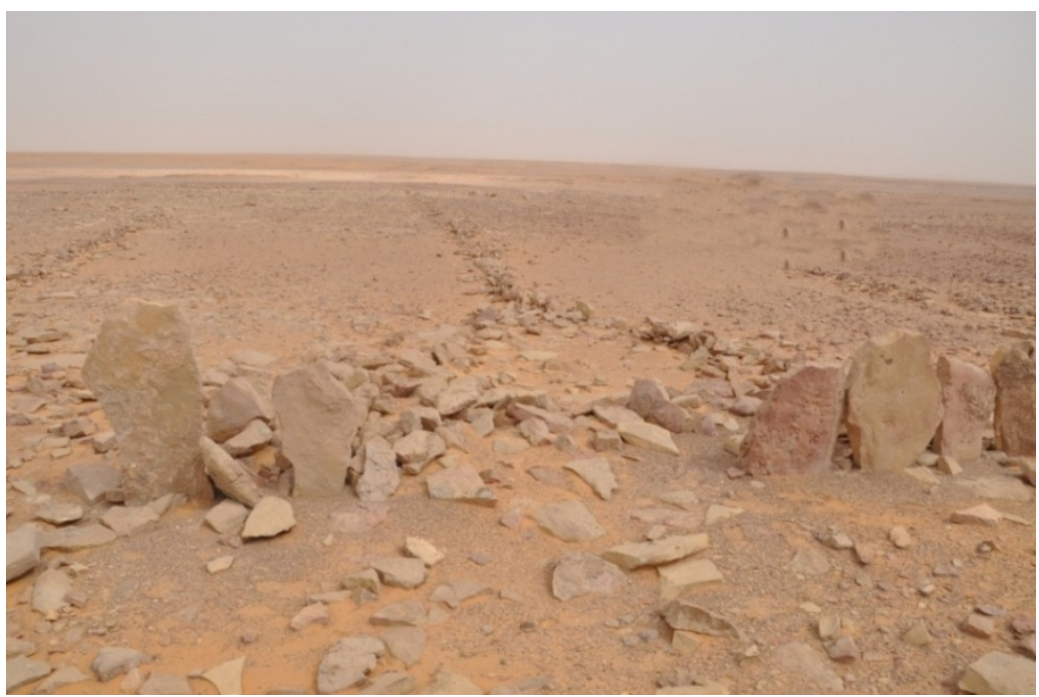

Figure 23. Triangular shaped long stone structure at al-Fao (Courteously Mhammad al Shawati).

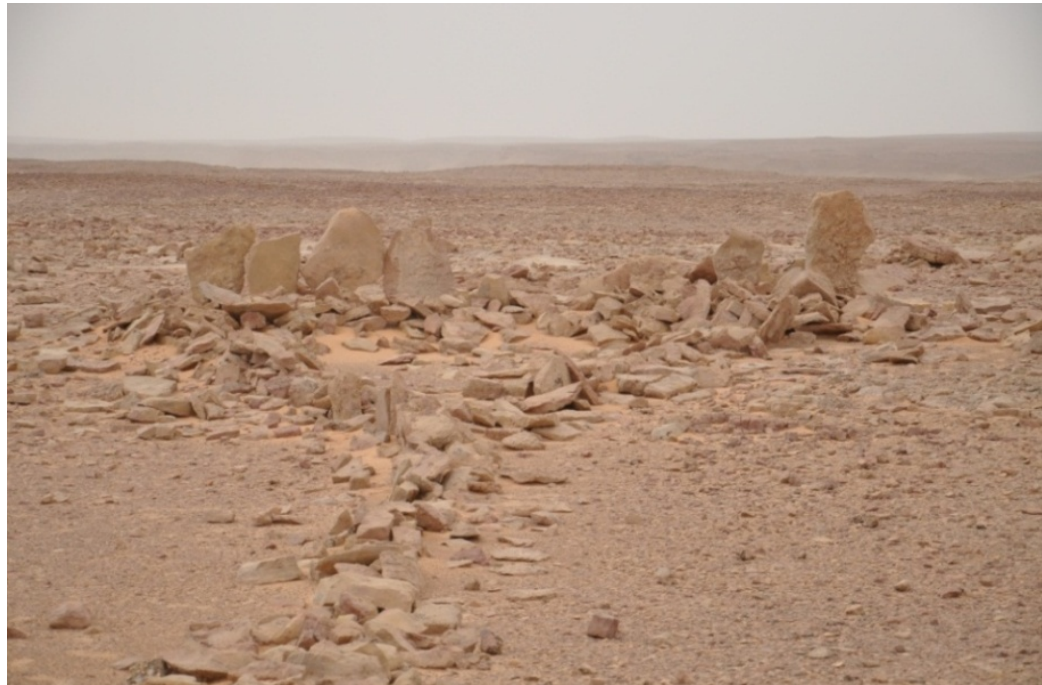

Figure 24. Triangular head and a long tailed structure extending to about 25 meters located at al-Fao, southern region (Courtesy Mohammad al Showati).

These structures in mid desert with no associated cultural objects pose a problem of their purpose, function, or use. Several of these structures lay close to each other in the desert. Excavations of the middle mound and nearby areas revealed nothing and the mystery remains as such until now. Stones were brought from where else and placed systematically in proper order to form circles and kite like structure (see Figures 25, 26, 27, \& 28). 


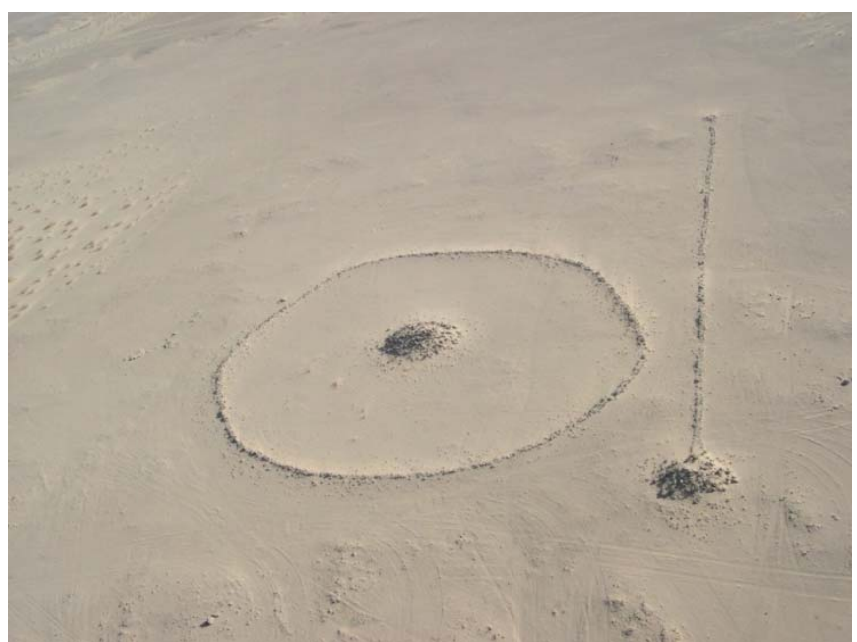

Figure 25. Aerial view of a large circle and nearby kite like large structure from the Great Arabian desert "Rub al-Khali” or the Empty Quarter. ${ }^{10}$

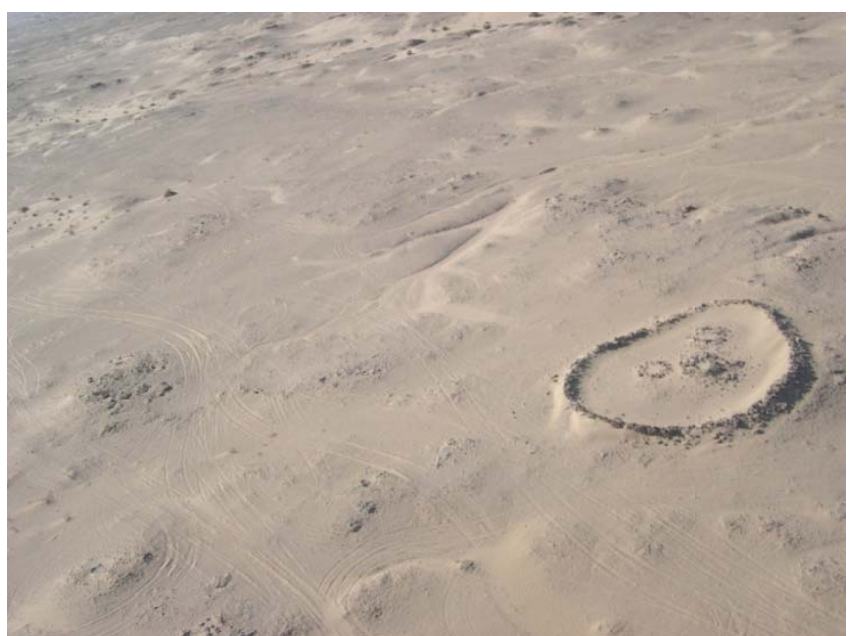

Figure 26. Large circular structure with three small circular structures inside it joined a triangular form (courtesy Dr. Awadhal-Zahrani).

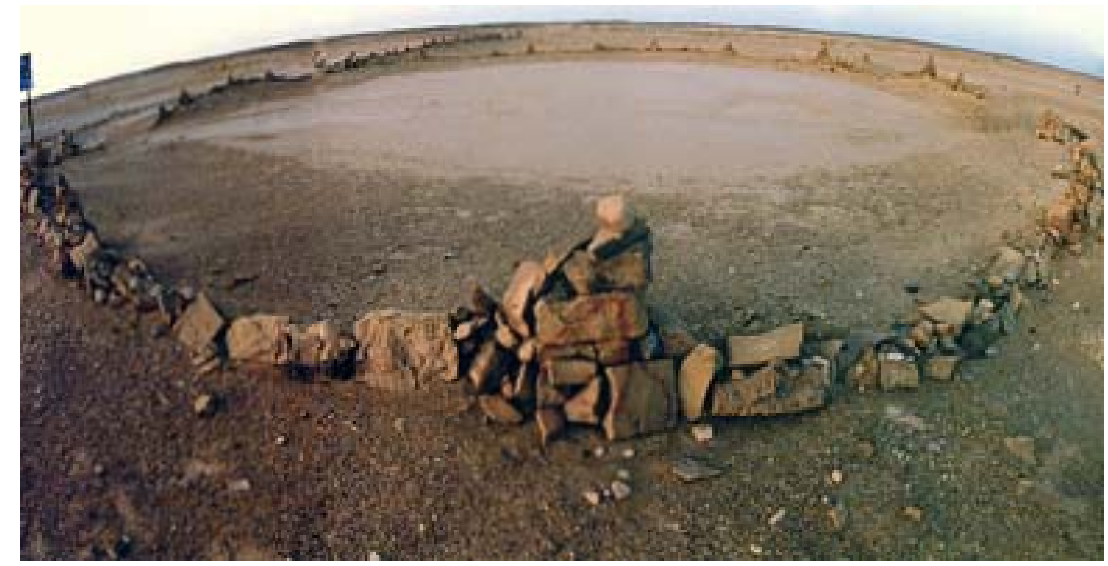

Figure 27. Closer view of a large circular structure from Tayma, northwest of the country.

\footnotetext{
10 These are found in isolation at far off places from any settlement areas make them mysterious and unsolved and un-understandable. (courtesy Dr. Awadhal-Zahrani).
} 


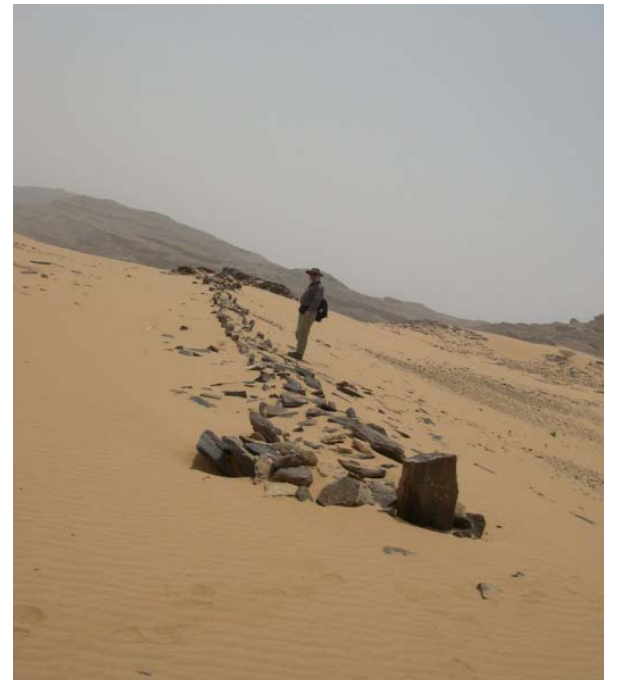

Figure 28. Circular structure or piles of stones joined by a long stone wall with another circular structures in the desert near Himma, southern region.

\section{Conclusion}

The rock art of Saudi Arabia represents various phases of cultural periods from Neolithic until recent past. Similarly, stone structures, cairns, kites, and circular shaped structures in isolated places and in deep deserts suggest the people living in the Arabian deserts had a variety of beliefs, religious entities, thoughts, and philosophical perspective about metaphysical and cosmological world. The ancient Arabs, like any other nations of the world left their cultural treasure in the form of petroglyphs, painted images and stone objects, and a variety of stone structures all over the Arabian Peninsula. The mysteries and mysticism associated with these structures and petroglyphs shall remain unsolved. Although, we have no means to understand them but we have means to preserve and protect them as the cultural heritage of our ancestors.

\section{References}

Bednarik, R. G., \& Khan, M. (2002). The Saudi Arabian rock art mission of November 2001. Atlal, 17, 75-99.

Bednarik, R. G., \& Khan, M. (2005). Scientific study of Saudi Arabian rock art. Rock Art Research, 22(1), 49-81.

Clarke, C. (1970). Rock art at Jubbah, northern Saudi Arabia. Proceedings of the Seminar for Arabian studies. London: Institute of Archaeology.

Clarke, C. (1975). Rock art in the Oman Mountains. Proceedings of the Seminar for Arabian Studies. London: Institute of Archaeology.

Field, H. (1952). Camel brands and graffiti from Iraq, Syria, Jordan, Iran and Saudi Arabia. Supplement to the Journal of American Oriental Research, 72(4), 1-26.

Khan, M., Kabawi, A., \& Al-Zhrani, A. (1986). Preliminary Report on the Second Phase of Rock Art and Epigraphic Survey of Northern Saudi Arabia. Atlal, 10, 255-265.

Khan, M. (1988a). Rock art and epigraphic survey of northern Saudi Arabia. Atlal, 11, 61-76.

Khan, M. (1988b). Schematization and form in the rock art of northern Saudi Arabia. Atlal, 11, 93-95.

Khan, M. (1990). Art and Religion: Sacred Images of Prehistoric Metaphysical World. Atlal, 12, 61-67.

Khan, M. (1991a). Female Profile Figures from WadiDamm, NW Saudi Arabia. Atlal, 1, 61-67.

Khan, M. (1991b). Recent rock art and epigraphic investigations in Saudi Arabia. Proceedings of the Seminar for Arabian Studies. University of London.

Khan, M. (1993b). Origin and evolution of ancient Arabian inscriptions. Riyadh: The Ministry of Education.

Khan, M. (1993c). Prehistoric rock art of northern Saudi Arabia (Ph.D. Thesis, University of Southampton). 
Khan, M. (1996). Rock art research in the Arabian Peninsula, Levant and Anatolia. News of the World, 1, 95-103.

Khan, M. (1998). A critical review of rock art studies in Saudi Arabia. East and West, 48(3), 427-437.

Khan, M. (1999). Human figures in the rock art of Saudi Arabia. Publications of the International Rock Art Congress, Ripen, Wisconsin USA.

Khan, M. (2000a). Wusum-The tribal symbols of Saudi Arabia. Riyadh: The Ministry of Education.

Khan, M. (2000b). BirHimma-The center of prehistoric art and culture. Admatu, (6), 27-34.

Khan, M. (2005). Jubbah—the most prominent rock art site of Saudi Arabia. Indo-Koko-Kenkyu, 26, 63-72.

Khan, M. (2007a). Sacred Images of Metaphysical World-Perspective of Prehistoric Religion in Arabia. XXII Valcamonica Symposium. Rock Art in the frame of the Cultural Heritage of Humankind papers.

Khan, M. (2007b). Rock art of Saudi across twelve thousand years. Riyadh: The Ministry of Education.

Khan, M. (2008). Rock art studies (How to study rock art). Riyadh: The Ministry of Education.

Khan, M., \& Bednarik, R. (2009). The rock art of southern Arabia “Reconsidered”. Adumatu, 20, 7-20.

Khan, M. (2010). Jubbah-the land of golden sand and the lost civilization of Arabia. Riyadh: The Saudi Commission for Tourism and Antiquities.

Khan, M. (2012). Arabian horse-Origin, development and history. Riyadh: Layan Cultural Foundation.

Zarins, J. (1979). Rajajil: A unique Arabian site from the fourth Millennium B.C.. Atlal, 3, 73-78. 